\title{
Fabricación de una superaleación de base níquel con estructura celular y microporosidad interconectada
}

\author{
A. Bernabé ${ }^{(*)}$, E. López ${ }^{(*)}$ y J. Gil-Sevillano ${ }^{(*)}$ \\ Resumen En este artículo se describe la preparación y caracterización de una superaleación de base níquel de \\ microporosidad controlada, partiendo de una aleación pesada W-Ni-Fe de naturaleza densa y con \\ métodos electrolíticos. Se ha conseguido un proceso factible de fabricación y, simultáneamente, una \\ oportunidad de reciclado de las virutas de mecanizado de metal pesado. Tanto el nuevo material \\ como el proceso de obtención han sido objeto de patente (Núm. P9700191, 1997). El nuevo material \\ podría ser interesante como soporte de catalizadores, filtro de fluidos corrosivos a temperaturas ele- \\ vadas, difusor en quemadores, etc.
}

Palabras clave: Materiales celulares. Materiales porosos. Superaleaciones. Metal pesado. Aleaciones de volframio.

\section{Development of a Ni-based superalloy with cellular structure and interconnected microporosity}

\begin{abstract}
A cellular metallic material with interconnected porosity of controlled size of an order of $10 \mu \mathrm{m}$ has been developed by electrochemical dissolution of tungsten grains in a W-Ni-Fe heavy alloy. The nickel superalloy with sponge structure and high surface/volume ratio can also be processed recycling chips from heavy metal machining (Patent $n^{\circ}$ P9700191, 1997). Applications for the new material could be found as support for catalysts, high temperature filters for corrosive fluids, burners, etc.
\end{abstract}

Keywords: Cellular materials. Porous materials. Superalloys. Heavy metal. Tungsten alloys.

\section{INTRODUCCIÓN}

Un material celular está compuesto por una sucesión de celdas o poros interconectados. Se pueden citar multitud de ejemplos de materiales naturales: la madera, el corcho, los panales de las abejas, los corales. En los últimos años, el hombre ha sido capaz de fabricar nuevos materiales celulares de naturaleza polimérica, cerámica, metálica o vítrea. Consecuentemente, cada vez aparecen nuevas aplicaciones para el uso técnico de los materiales celulares (alta relación superficie/volumen, muy baja densidad, alta capacidad de absorción de energía, filtración de líquidos o gases, etc.)(1-5).

(*) CEIT (Centro de Estudios e Investigaciones Técnicas de Guipúzcoa y E.S.I.I. (Univ. de Navarra). Po. M. de Lardizábal, 15, 20009-San Sebastián (España).
Las aleaciones W-Ni-Fe se fabrican por compactación en frío de polvos metálicos, seguida de sinterización en fase líquida. Durante este último proceso, la fase líquida de níquel y de hierro disuelve una pequeña cantidad de volframio y moja los granos sólidos de este último elemento. Estas partículas sólidas de volframio crecen, tanto por un proceso de disolución y reprecipitación, como por coalescencia. Después de la sinterización, la microestructura resultante es una red interconectada de granos de volframio esferoidales cuyo tamaño (de 10 a 50 $\mu \mathrm{m})$ se puede controlar ajustando la temperatura y el tiempo de sinterizado. Los granos de volframio están rodeados por una matriz continua c.c.c. de níquel, hierro y volframio, que ocupa entre un 15 y un $25 \%$ del volumen (6-9).

Para fabricar el material celular partiendo del metal pesado, se han empleado técnicas de electrólisis, que permiten eliminar selectivamente la fase 
volframio de la aleación. De esta forma, se ha conseguido generar una capa de estructura celular, donde las celdas corresponden a los espacios que ocupaban los granos de volframio eliminados y las paredes, a la fase matriz, que no se elimina. El nuevo material buscado es una esponja de superaleación de base níquel (50\% Ni- $25 \% \mathrm{Fe}-25 \% \mathrm{~W}$ ) con una densidad aparente muy baja y una relación superficie/volumen muy alta.

El espesor de material celular obtenido mediante electrólisis de probetas densas de aleación pesada es relativamente pequeño y esta técnica sólo puede emplearse económicamente para fabricar membranas porosas delgadas o superficies porosas de piezas macizas. Por ello, se ha desarrollado otra técnica para fabricar material celular sin limitaciones de tamaño. Dicha técnica consiste en sinterizar, en fase sólida, viruta de aleación pesada procedente de mecanizado, para obtener un material con gran macropososidad inicial. Posteriormente, los sinterizados de virutas se atacan electrolíticamente, con el mismo método que el empleado con las probetas densas. La macroporosidad permite el flujo fácil del electrólito y para cada viruta la disolución del volframio es completa, quedando un esqueleto de capas de matriz porosa soldadas entre si. Esta técnica permite reciclar virutas de mecanizado de metal pesado, dando lugar a un nuevo material potencialmente interesante. Además, el volframio puede recuperarse del electrólito mediante procesos químicos y reciclarse para la producción de metal pesado. El reciclado de metal pesado, material muy caro, no es nada fácil y constituye un problema que está siendo objeto de investigación en otros países.

\section{TÉCNICAS EXPERIMENTALES Y RESULTADOS}

\subsection{Material base}

Se partió de metal pesado con $93,4 \% \mathrm{~W}$ (en masa), fabricado previamente en el CEIT por sinterizado en fase líquida (Fig. 1). La fracción volumétrica de matriz es del $12 \%$ y el tamaño medio de los granos globulares de volframio es de $27 \mu \mathrm{m}$ (intersección lineal media) (8).

\subsection{Electrólisis de probetas de aleación pesada}

El objetivo de los ataques electrolíticos es determinar el espesor de material celular obtenido en función del tiempo de ataque. Para ello, se utilizó como ánodo la probeta de metal pesado y como cátodo un electrodo de carbono. Entre las distintas posibilidades de eliminación de la fase volframio,

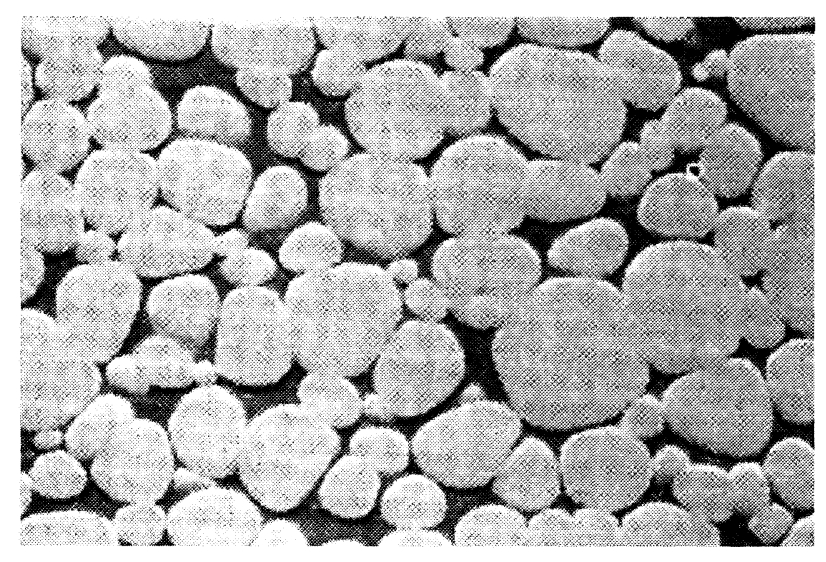

Fig. 1.- Sección transversal del "metal pesado" con $93,4 \%$ W utilizado para las experiencias de disolución electrolítica del volframio.

\section{FIG. 1.- Heavy metal W-Ni-Fe (93.4\% W). SEM.}

se eligió como electrólito una disolución $2 \mathrm{SO}_{4} \mathrm{Cu} / 1 \mathrm{NH}_{4} \mathrm{OH}$, debido a resultados experimentales obtenidos con anterioridad, en los que se observó producción de pozos de ataque, con eliminación de volframio y apenas disolución de matriz. La diferencia de potencial utilizada fue de $6 \mathrm{~V}$.

Para la observación de los resultados de los ataques electrolíticos, las probetas, tras el ataque, se han engastado en vacío con resina epoxy, a fin de llenar los poros de la estructura celular, localmente muy delicada, darle consistencia y posteriormente poder cortar las probetas sin daño. Hay que tener en cuenta que, aproximadamente, el tamaño del $80 \%$ de las celdas está comprendido entre 15 y $50 \mu \mathrm{m}$ y que sus paredes y columnas son extremadamente delgadas. Las probetas han sido sometidas a distintas series de ataques consecutivos, de duración constante, y el electrólito ha sido renovado después de cada ataque.

La mayor eficacia de pérdidas medias de masa eliminada por ataque se obtiene con ataques de 10 min. Esta eficacia va disminuyendo a medida que las probetas sufren más ataques. Este resultado se comprueba con los datos del espesor de material celular obtenido (Fig. 2), en donde el máximo de volframio eliminado alcanza las $200 \mu \mathrm{m}$ para una serie de ocho ataques parciales de $10 \mathrm{~min}$. La figura 3 muestra la morfología del material celular obtenido. En ella, también se aprecia cómo la matriz, que forma las paredes de las celdas, se deteriora progresivamente en sus bordes, lo cual impide prolongar indefinidamente el tiempo de ataque electrolítico.

Para la obtención de piezas celulares masivas se ha desarrollado otro proceso, basado en la sinterización en fase sólida de virutas de mecanizado de espesor inferior a $500 \mu \mathrm{m}$, método que se describe a continuación. 


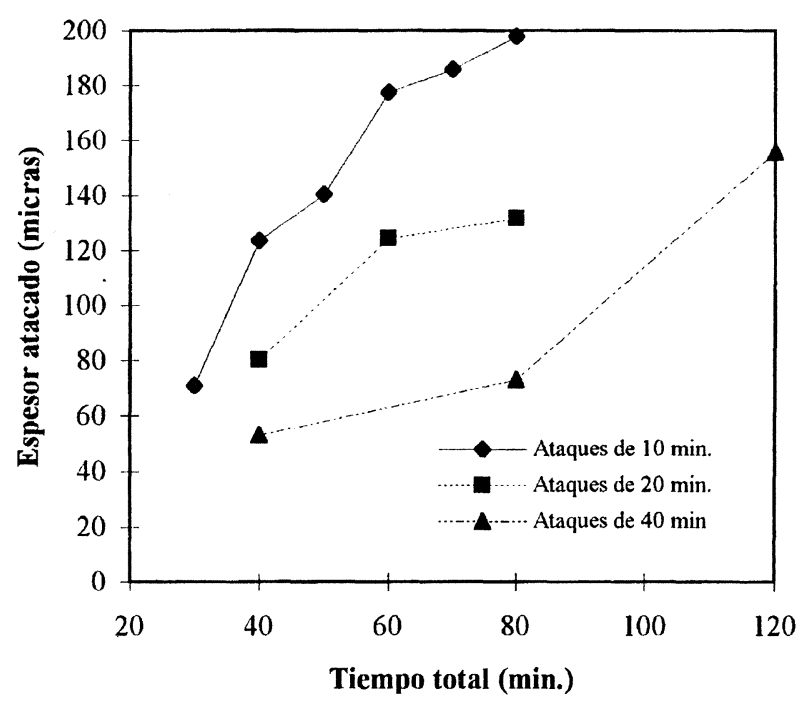

FIG. 2.- Espesor de material celular obtenido en función del tiempo de ataque electrolítico.

FIG. 2.- Thickness of cellular material layer as a function of time of the electrolitic dissolution of tungsten.

\subsection{Electrólisis de virutas de aleación pesada}

La viruta ha sido compactada en frío de forma uniaxial, para obtener probetas de distintas formas geométricas. La compactación da lugar a aglomerados con una densidad relativa aproximada del $56 \%$. Se han sometido, después, a un ciclo de sinterización a $1.450{ }^{\circ} \mathrm{C}$ durante $60 \mathrm{~min}$. La electrólisis ha sido realizada empleando la misma técnica que para el ataque de probetas densas, descrito anteriormente, utilizándose probetas en forma de paralelepípedos (Fig. 4). En la figura 5 se muestra la evolución de la densidad relativa en la serie de ataques a unas determinadas probetas. Se han obtenido muestras con densidades relativas entre el 20 y el $40 \%$ de la densidad teórica. La figura 6 muestra la evolución de una probeta durante la serie de seis ataques electrolíticos de 10 min a los que ha sido sometida. En la imagen $a$ ), tras el primer ataque, se observa cómo se ha eliminado ya parte de la fase volframio. La imagen $b$ ) corresponde a tres ataques. La tercera imagen, $c$ ), corresponde al estado final de la probeta, tras seis ataques.

El comportamiento mecánico del nuevo material a temperatura ambiente es el típico de los materiales celulares (1), con una buena capacidad de absorción de energía mecánica, como se puede observar en la figura 7 , donde se muestran los resultados de dos ensayos de compresión.

\section{POSIBLES APLICACIONES DEL NUEVO MATERIAL}

El nuevo material podría emplearse como soporte de catalizadores. Su superficie por unidad de
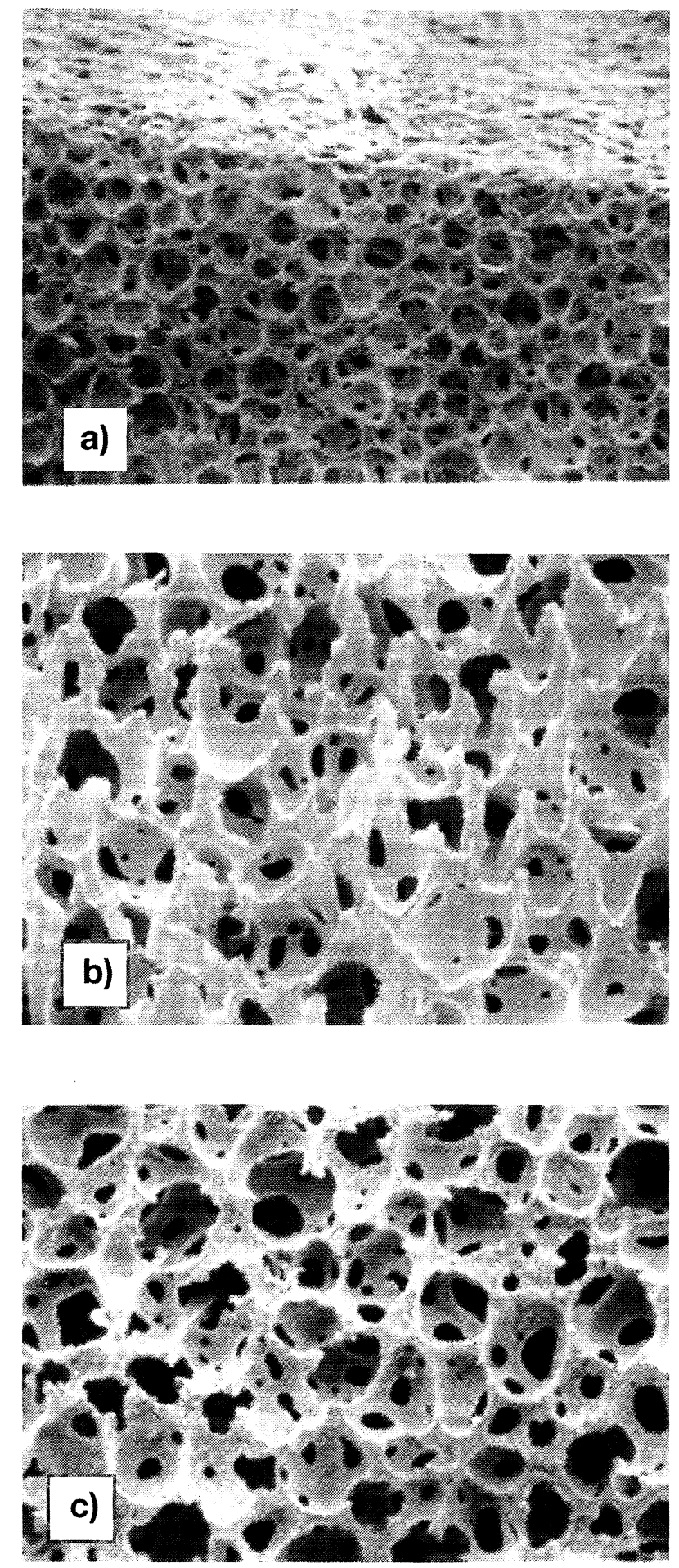

FIG. 3.- a) Morfología del material celular después de distintos tiempos de ataque. a) Ataque: $4 \times 10$ min. b) $7 \times 10$ min. c) $8 \times 10 \mathrm{~min}$.

FIG. 3.- Morphology of the cellular material after different etching times. Etch: a) $4 \times 10 \mathrm{~min}$. b) $7 \times 10$ min. c) $8 \times 10 \mathrm{~min}$.

volumen es $S_{\mathrm{v}} \approx 60 \mathrm{~mm}^{-1}$ y el tamaño de sus poros, controlable. Podría emplearse como distribuidor de gas en quemadores de calderas, consiguiendo una distribución de llama homogénea. También podría 


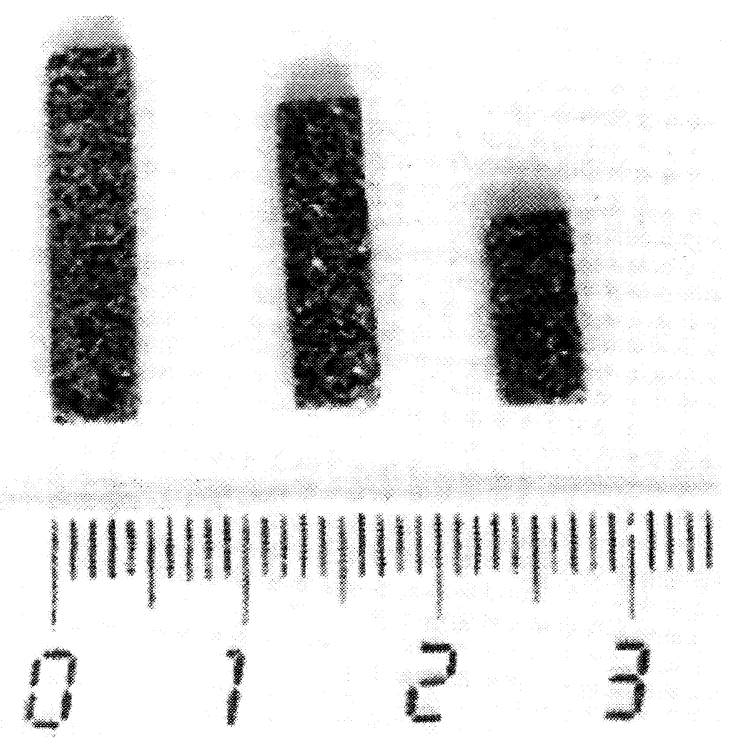

FIG. 4.- Probetas preparadas para el ataque electrolítico.

FIG. 4.- Samples of compacted machining chips after solid state sintering before electrolytic etching.

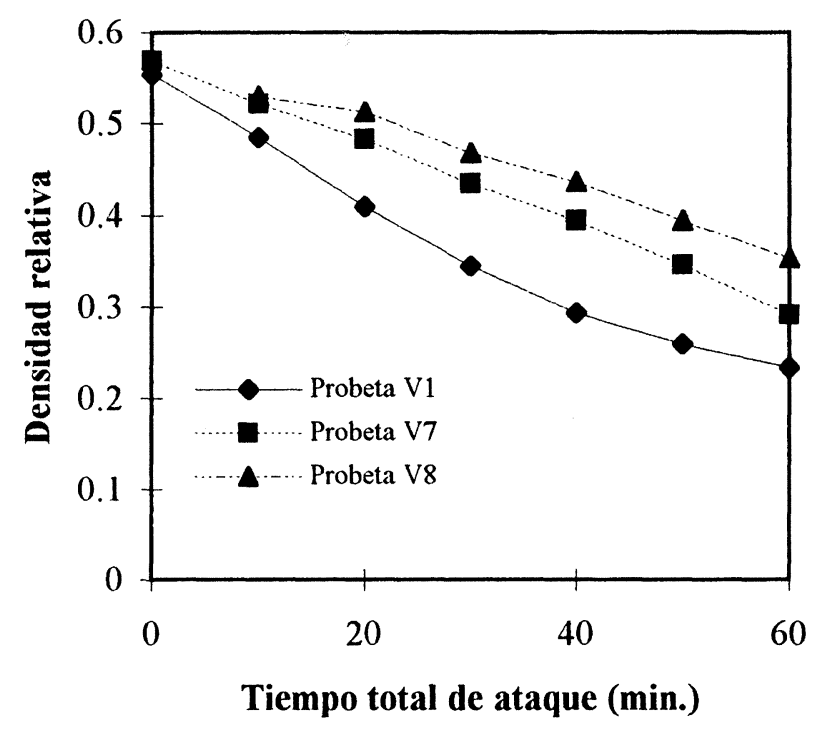

FIG. 5.- Densidad relativa $v s$ tiempo de ataque electrolítico.

FIG. 5.- Relative density vs time of electrolytic etching.

aplicarse como filtro para líquidos o gases corrosivos, a temperaturas elevadas. Dos características muy importantes del nuevo material son su resistencia mecánica a alta temperatura, por su composición, y su resistencia a la oxidación, por su alto contenido de níquel.

Finalmente, una aplicación no desdeñable a considerar para este material es la de electrodo para células de combustible, en particular células que trabajen entre 600 y $1.000^{\circ} \mathrm{C}$, quizás como sustituto
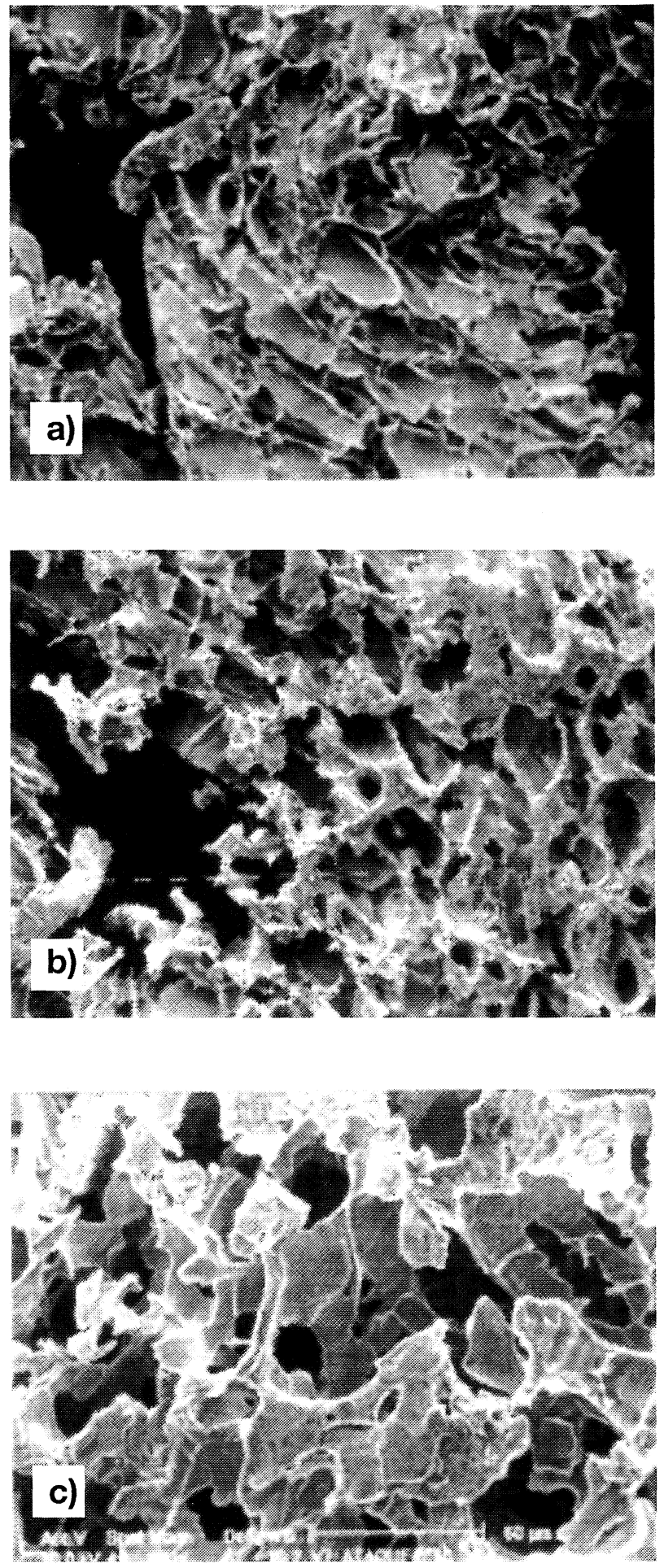

FIG. 6.- Imágenes SEM de la microestructura del material poroso obtenido de virutas de mecanizado del material sinterizado después de tiempos de ataque crecientes : a) $10 \mathrm{~min}$, b) $30 \mathrm{~min}$ y c) $60 \mathrm{~min}$.

FIG. 6.- SEM images of the microstructure of the porous material from sintered machining chips after increasing etching times: a) $10 \mathrm{~min}$, b) $30 \mathrm{~min}$ y c) $60 \mathrm{~min}$.

de los cermets $\mathrm{Ni}-\mathrm{ZrO}_{2}$ que se usan como ánodo en las células de combustible de óxidos sólidos (10). 


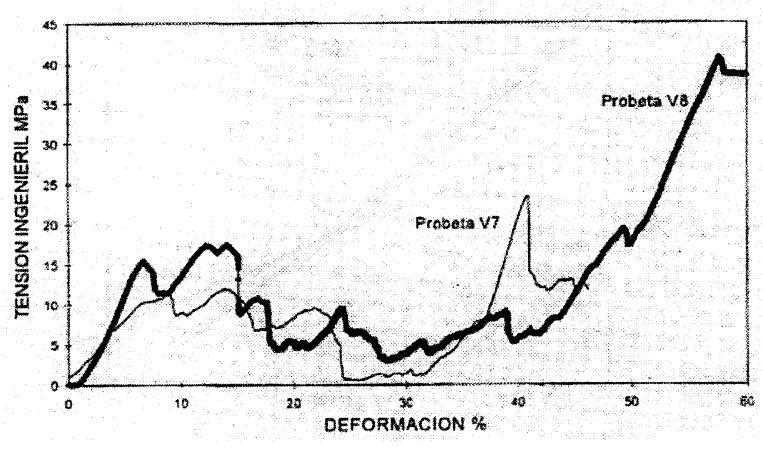

FIG. 7.- Curva de compresión del material celular obtenido por reciclado de virutas de metal pesado y disolución electrolítica del volframio.

FIG. 7.-Stress-strain response compression testing of the cellular material obtained from recycled machining chips of heavy metal.

\section{CONCLUSIONES}

Se ha desarrollado un nuevo material metálico poroso (celular) potencialmente muy interesante, cuya materia prima es metal pesado convencional. En una de sus variantes, el proceso recicla residuos de mecanizado, difícilmente aprovechables, de ese material, muy caro.
El material tiene una morfología esponjosa con células interconectadas, cuyas paredes son de una superaleación de base níquel, con buena resistencia mecánica, térmica y química. El diámetro medio de los poros puede controlarse y oscilar, típicamente, entre 10 y $50 \mu \mathrm{m}$.

\section{REFERENCIAS}

(1) Gibson, L.J. y Ashby, M.F. Cellular Solids. Structure \& Properties, Pergamon Press, 1988 ( $2^{\mathrm{a}}$ Ed., Cambridge University Press, 1997).

(2) Judge, M. New Scientist. Sept. 27, 1997: 34.

(3) Bauhart, J., Baumesiter, J. y Weber, M. Metal Powder Rep., Abril, 1997: 38.

(4) DAvies, G.J. y ZeN, S. J. Mater Sci., 18, 1983: 1.899.

(5) Sherman, A.J. Ceramic Bull., 70 (6), 1991: 1.025.

(6) Ostolaza, K. Tesis Doctoral, E.S.I.I., Donostia-San Sebastián (España). 1992.

(7) Bernabé, A. "Encuentros en la interfase, II". CEIT, 1991.

(8) Bernabé, A. Tesis Doctoral, E.S.I.I., Univ. de Navarra, 1998.

(9) Stephen, S.W.H. y WANG, T.C. Tungsten. Sources, Metallurgy, Properties and Applications, Plenum Pub. Corp. Nueva York (EE.UU.) 1979.

(10) Kordesch, K. y Simader, O. Fuel Cells and their Applications. VCH, Weinheim (Alemania), 1996. 